\title{
Direct Torque Control of Induction Motor Load
}

\section{Generator}

Hamid R. Tolue

Technical University of Lisbon, Lisbon, Portugal

\begin{abstract}
DTC (direct torque control) of induction motor drives has many outstanding performance and implementation properties. This paper presents an innovative direct torque controlled load generator based on space vector modulation suitable for the emerging applications such as electrical test benches that require extremely fast large-signal torque and dynamic responses. To realize system performance, two methods based on the classical DTC (with six-sector switch table) and the proposed twelve-sector DTC have been analyzed and used for modelling the dynamometer. The performance of the proposed dynamometer is investigated by simulating different parts of the system and results are presented for several industrial load profiles. Finally, limitations and advantages of each controller are presented and analyzed.
\end{abstract}

Key words: DTC, motor control, induction motor, load generator.

\section{Introduction}

As most industrial loads are nonlinear and time variant, realizing the actual load conditions for testing motors and drive systems in laboratory environments can help with understanding their complex behavior [1-7]. Test bench is a proper device for achieving this target. It is composed of three main parts: dynamometer including its control unit, data processing system and the motor under test. Dynamometer is used to produce the appropriate mechanical load profiles, the electrical machine (motor under test) is mounted and its transient and steady state characteristics are determined [2,8].

An advanced application of the load generator is in the roll test of vehicles where one motor drives another. Therefore, the vehicle can accelerate, decelerate or brake under various operating conditions. The car speed can be adjusted by changing the output torque of the load generator. In the classical dynamometer, the load is adjusted by altering the frictional drag or the electrical output torque of the generator or by changing

Corresponding author: Hamid R. Tolue, Ph.D. student, research fields: power electronics, reactive power control, motor drives, decentralized control. the slip. In both cases, the load is passive and the machine can only be tested under steady state condition. In Ref. [9], the dynamometer is simulated for an induction. motor using the conventional vector control method.

Conventional vector control approaches usually have long response times and are not suitable for high speed applications. DTC (direct torque control) overcomes this limitation. Main drawbacks of DTC are relatively higher flux and torque ripples and variable inverter switching frequency. In Ref. [10], a prominent DTC scheme for IPMSM (interior permanent magnet synchronous machine) is investigated which features in very low flux and torque ripple and almost fixed switching frequency. In Refs. [11, 12], excellent dynamic behavior of the system with varying the load parameters is described and explained in more details.

In this paper, two new approaches based on DTC with six-sector switch table and improved DTC with twelve-sector switch table for the load generator system are proposed, analyzed and simulated based on space vector modulation. Precise models of different parts of the system are described in SIMULINK/MATLAB and some typical (static and 
dynamic) industrial loads are generated and imposed on the motor under test. Simulation results show that the static and dynamic characteristics of industrial linear and nonlinear loads can be modelled precisely for the motors and drives under test.

Methods of DTC are presented in Section 2. Section 3 discusses the modelling of induction motor load generator system. It is assumed that the torque characteristic of the arbitrary load is known and can be modelled using a polynomial with coefficients of speed, inertia and their derivatives. Section 4 provides simulation results followed by conclusions.

\section{Methods of DTC}

In 1986, Takahashi introduced the idea of direct torque control (DTC) with bang-bang control that performs very well with on-off operation of the inverter semiconductor power devices. The idea was further developed by M. Depenbrock as DSC (direct self-control). DTC of inverter-fed induction motor is carried out by hysteresis control of stator flux and torque magnitude that selects one of the six non-zero and two zero inverter space vectors as shown in Fig. 1. The advent of this method in industrial application was in 1998 by ABB [13].

$$
T_{e}=\frac{3}{2} P \frac{L_{m}}{L_{s} L_{r}-L_{m}^{2}}\left|\Psi_{r}^{\prime}\right|\left|\Psi_{s}\right| \sin \left(\rho_{s}-\rho_{r}\right)
$$

Eq. (1) shows the formula to calculate electrical torque, where cross sign indicates the vector product, $\left|\Psi_{S}\right|,\left|\Psi_{r}^{\prime}\right|, \rho_{S}$ and $\rho_{r}$ are magnitudes and phases stator and rotor fluxes respectively. $L_{m}$ is the mutual inductance, $L_{s}$ and $L_{r}$ are stator and rotor inductances respectively, and $P$ is the number of pole pairs. Because rotor time constant is larger than stator time constant, the rotor flux changes slowly compared with the stator flux; in fact, the rotor flux can be assumed constant. Neglecting ohmic losses, stator voltage directly influences stator flux in accordance with the following equation:

$$
\begin{gathered}
\frac{d \Phi_{S}}{d t}=V_{S} \\
\Delta \Phi_{S}=V_{S} \Delta t
\end{gathered}
$$

Fig. 1 shows the possible dynamic locus of the stator flux and its variations depending on the selected VSI states. The possible global locus is divided into six different sectors separated by discontinuous lines [3]. In this figure, voltage vectors are identified with three digits. Each digit (0 or 1) shows the state of the switch of the corresponding phase where the order of switches

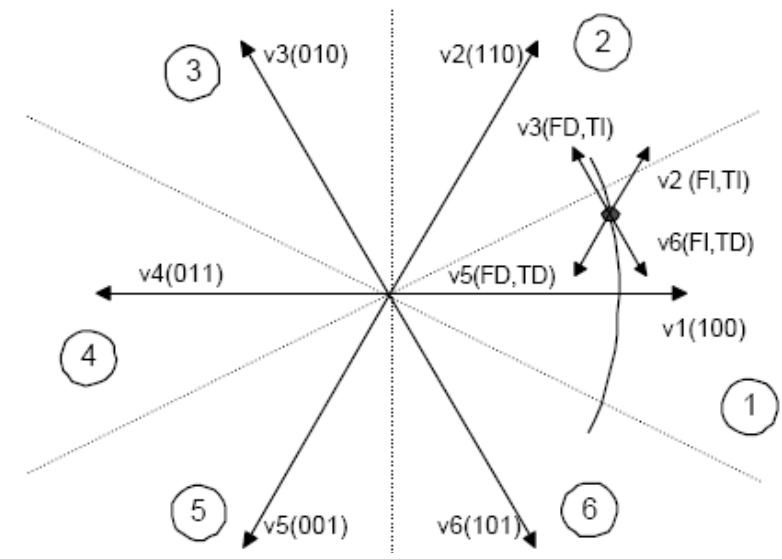

Fig. 1 Stator flux vector locus and different possible switching voltage vectors (FD: flux decrease, FI: flux increase, TD: torque decrease, and TI: torque increase).

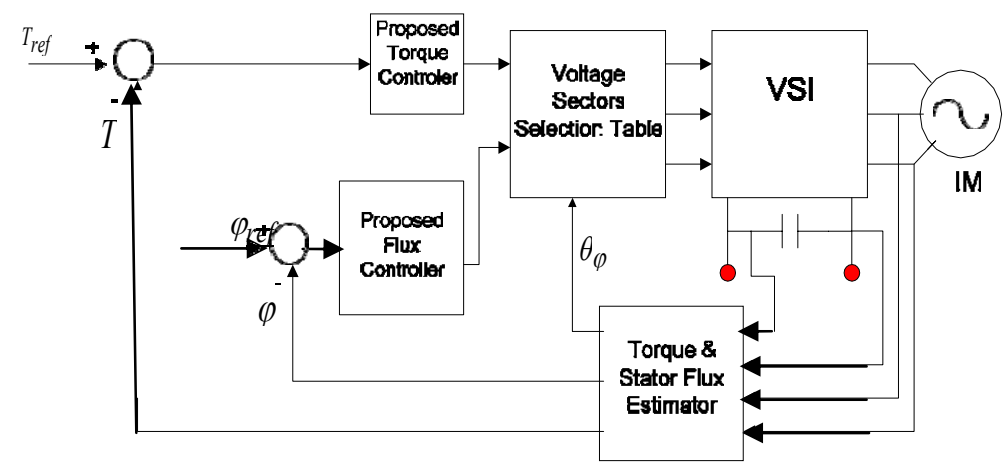

Fig. 2 Block diagram of direct torque control (DTC). 
is from left to right (Fig. 2). For example, $V_{A}=$ $V 1$ (100) shows that high side on the first leg, and bottom switches on the second, and third legs are on and the other transistors are off. In accordance with Fig. 1, general selections of voltage states are listed in Table 1.

Note that for each sector, states $V_{K}$ and $V_{K+3}$ are not considered in the torque calculations since torque cannot simultaneously increase (first 30 degrees) and decrease (second 30 degrees) at the same sector depending on the stator flux position. A possible schematic of direct torque control is shown in Fig. 2. There are two different loops corresponding to the magnitudes of the stator flux and torque. The reference stator flux and torque are compared with the actual values and the resulting errors are fed into two-level and three level hysteresis blocks, respectively. Outputs of hysteresis blocks with the position of the stator flux that can be in any of the six sectors are used as inputs of the look up table. There are other methods for decreasing the output torque ripples that can be used in the control section of load generator system $[3,4,6]$.

For solving the problem of flux and torque ambiguity, this paper presents the twelve-sector DTC as shown in Fig. 3. In this state, the tangential vector is relatively short and so the torque variations are very limited. TsI and TsD are associated with the slight increase and decrease of the torque, respectively, and are used in the hysteresis block with five stages [2].
The switch frequency of IGBTs should be selected similar to the real samples. Therefore, by using two hysteresis blocks, the region of differences between reference and actual (measured) values of torque and flux are coded. Under these conditions, the maximum value of switching frequency is calculated to be 18 $\mathrm{KHz}$.

\section{Modelling of Inductor Motor Load Generator}

The load torque of an induction motor can be described:

$T_{\text {load }}=T_{l s}+T_{l d}=\sum_{n=-\infty}^{\infty} A_{n} \omega_{m}^{n}+J_{l} \frac{d \omega}{d t}+D_{l} \omega_{m}(4)$

Where $T_{l s}$ and $T_{l d}$ are static and dynamic components of the load torque, respectively. Static torque characteristic presents the load torque for any steady state speed, $\omega_{m}$ is the angular speed of motor in $\mathrm{rad} / \mathrm{sec}$ and $A_{n}$ are constants that are selected according to the load characteristics. It should be noted that only a few terms of dynamic torque characteristic is a function of speed variations and shows load torque in the accelerating and decelerating intervals. If the $D_{l} \omega_{m}$ term in Eq. (4) is merged with one of the speed coefficients $\left(\sum A_{n} \omega_{m}\right), T_{l d}$ is attained for dynamic torque

Table 1 General selection table for DTC method.

\begin{tabular}{lll}
\hline Voltage vector & Increase & Decrease \\
\hline Stator flux & $V_{k}, V_{k+1}, V_{k-1}$ & $V_{k+2}, V_{k-2}, V_{k+3}$ \\
Torque & $V_{k+1}, V_{k+2}$ & $V_{k-1}, V_{k-2}$ \\
\hline
\end{tabular}

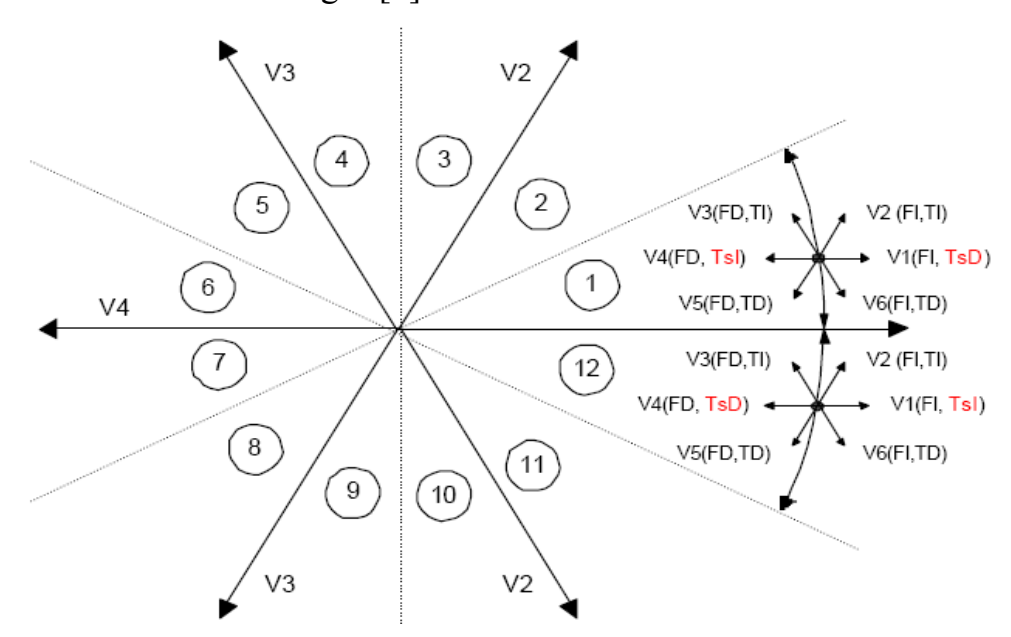

Fig. 3 Stator flux vector locus and different possible switching voltage vectors in the proposed twelve-sector DTC. 
of a rotational body. This term is positive (and added to load torque) in the accelerating interval, and negative (and added to dynamometer torque) in the deceleration interval, and zero under steady state conditions. Therefore, Eq. (4) is obtained for the load torque. As shown in Fig. 5, if the electric drive is used to rotate a mechanical load, we have:

$$
T_{\text {em }}-T_{\text {load }}=J_{m} \frac{d \omega}{d t}+D_{m} \omega_{m}
$$

Substituting Eq. (7) in Eq. (10):

$$
\begin{array}{r}
T_{e m}=J_{m} \frac{d \omega}{d t}+D_{m} \omega_{m}+\sum_{n=-\infty}^{\infty} A_{n} \omega_{m}^{n}+J_{l} \frac{d \omega}{d t}+ \\
D_{l} \omega_{m}(6)
\end{array}
$$

Let $J_{T}=J_{l}+J_{m}$ and combine the terms to get:

$$
T_{e m}=J_{T} \frac{d \omega_{m}}{d t}+\sum_{n=-\infty}^{\infty} A_{n} \omega_{m}^{n}
$$

In reality, dynamometer is substituted with the real load in an electrical test bench. Therefore, it should can produce (static and dynamic) torque speed characteristics of different loads. In this system, the LGM produces the desired load with DTC method and forces the MUT to perform with this condition. Based on Eq. (7), the arbitrary mechanical load can be expressed as:

$$
\begin{gathered}
T_{\text {load }}^{*}=A_{0}+A_{1} \omega_{m}+A_{2} \omega_{m}^{2}+A_{3} \omega_{m}^{3}+ \\
\cdots J_{e m} \frac{d \omega_{m}}{d t}+D_{\text {em }} \omega_{m}
\end{gathered}
$$

where, $A_{0}, A_{1}, A_{2} \ldots A_{n}$ are speed constants, $J_{e m}$ is the moment of inertia that must be generated by the dynamometer, and $\omega_{m}$ is the measured angular velocity (in $\mathrm{rad} / \mathrm{sec}$ ). Therefore, the real load torque that can be generated by the dynamometer is described as:

$$
\begin{aligned}
T_{\text {load-real }}^{*}= & A_{0}+A_{1} \omega_{m}+A_{2} \omega_{m}^{2} \ldots+\left(J_{e m}-\right. \\
& \left.J_{l}\right) \frac{d \omega_{m}}{d t}+\left(D_{e m}-D_{l}\right) \omega_{m}
\end{aligned}
$$

Finally, the system dynamic equation is:

$$
T_{m}-T_{\text {load-real }}=J_{m} \frac{d \omega_{m}}{d t}+D_{m} \omega_{m}
$$

and the rotational speed of rotor $\left(\omega_{m}\right)$ can be calculated as:

$$
\omega_{m}=\frac{1}{\left(J_{m}+J_{l}\right) S+\left(D_{m}+D_{l}\right)}\left(T_{m}-T_{l s}\right)
$$

\section{System Implementation}

After modeling the load generator system (Fig. 4), the load profile (including its static and dynamic components) should be applied to the dynamometer. For precise realization and easy comparison between different states with DTC, the desired load profile is selected and is used as the input of LGM. Note that LGM should operate in the generator region. Therefore, the rectifier must have the ability to return the energy to the power grid. This will considerably increase the computing time especially for applications requiring converter simulation for long durations.

\subsection{Results for Static Loads}

For the exertion of the proper load profile into the induction motor load generator, two identical 4hp motors (Table 2) are selected as LGM and MUT. The nominal torque of the motor is $19.8 \mathrm{NM}$. Simulation of final load generator system is shown in Fig. 6. It should be noted that the switching frequency of the IGBTs must be within the working frequency as described in the datasheet; therefore, a maximum frequency of 18 $\mathrm{kHz}$ has been selected which is in the available range. The reference flux is calculated using

$$
\lambda_{\text {ref }}=\frac{E_{e m f}}{4.44 f}=\frac{380 / \sqrt{2}}{4.44(50)}=1.2 \mathrm{~N} . \mathrm{wb}
$$

Simulation results for " $T_{r e f}=-10 N M$ ", and by using conventional and improved DTC methods are shown in Figs. 5 and 6 and Figs. 7 and 8, respectively. All simulated conditions show fine torque tracking characteristics. However, in the load generator system,

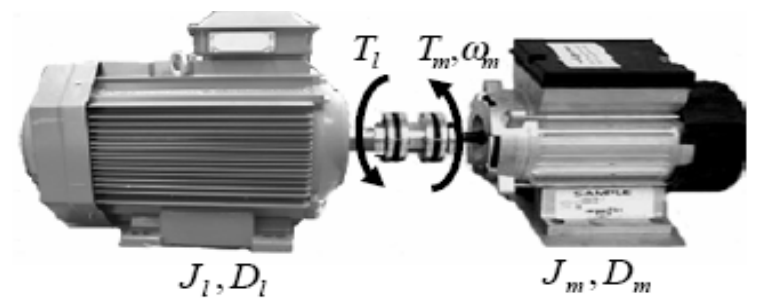

Fig. 4 MUT (motor under test) and the LGM (load generator motor) system. 
Table 2 Nominal parameter values for the 4HP motor.

\begin{tabular}{llllll}
\hline$V_{\text {line }}[V]$ & $R_{S}[\Omega]$ & $\mathrm{R}_{r}^{\prime}[\Omega]$ & $X_{l s}=\mathrm{X}_{l r}^{\prime}[\Omega]$ & $X_{m}[\Omega]$ & $J_{l}$ \\
\hline 380 & 8.28 & 6.166 & 9.92 & 244.23 & 0.02 \\
\hline
\end{tabular}
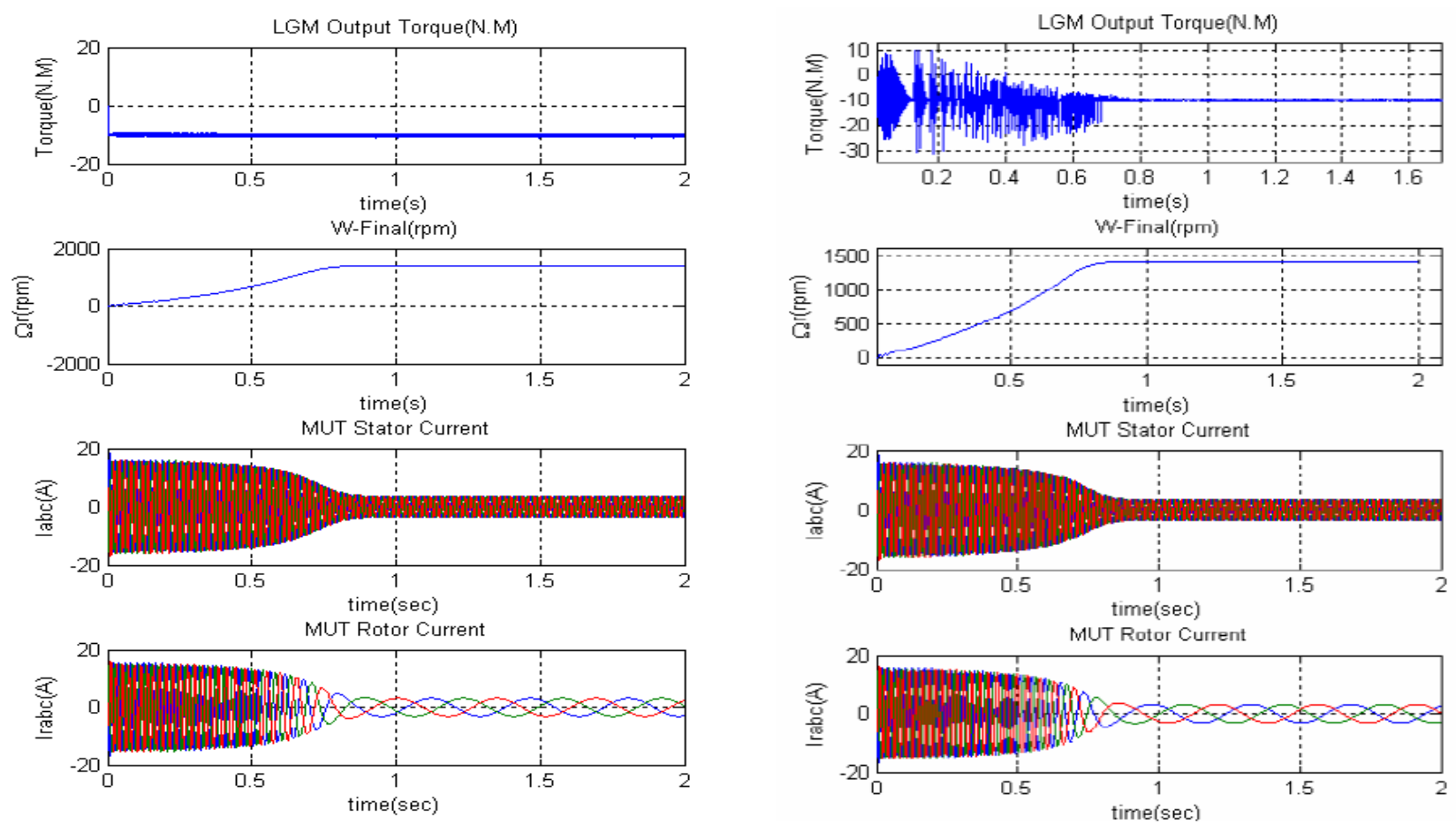

Fig. 5 Simulation results for Tref $=-10 N M$ by the conventional DTC: (a) output torque of LGM, (b) final speed of the system, (c) MUT stator current, (d) MUT rotor current.
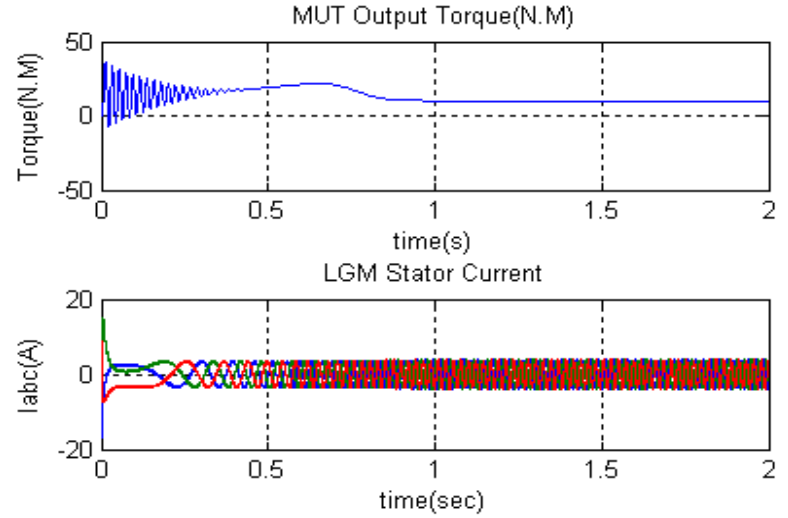

Fig. 7 Simulation results for Tref $=-10 \mathrm{NM}$ by the twelve-sector DTC: (a) output torque of LGM, (b) final speed of the system, (c) MUT stator current, (d) MUT rotor current.
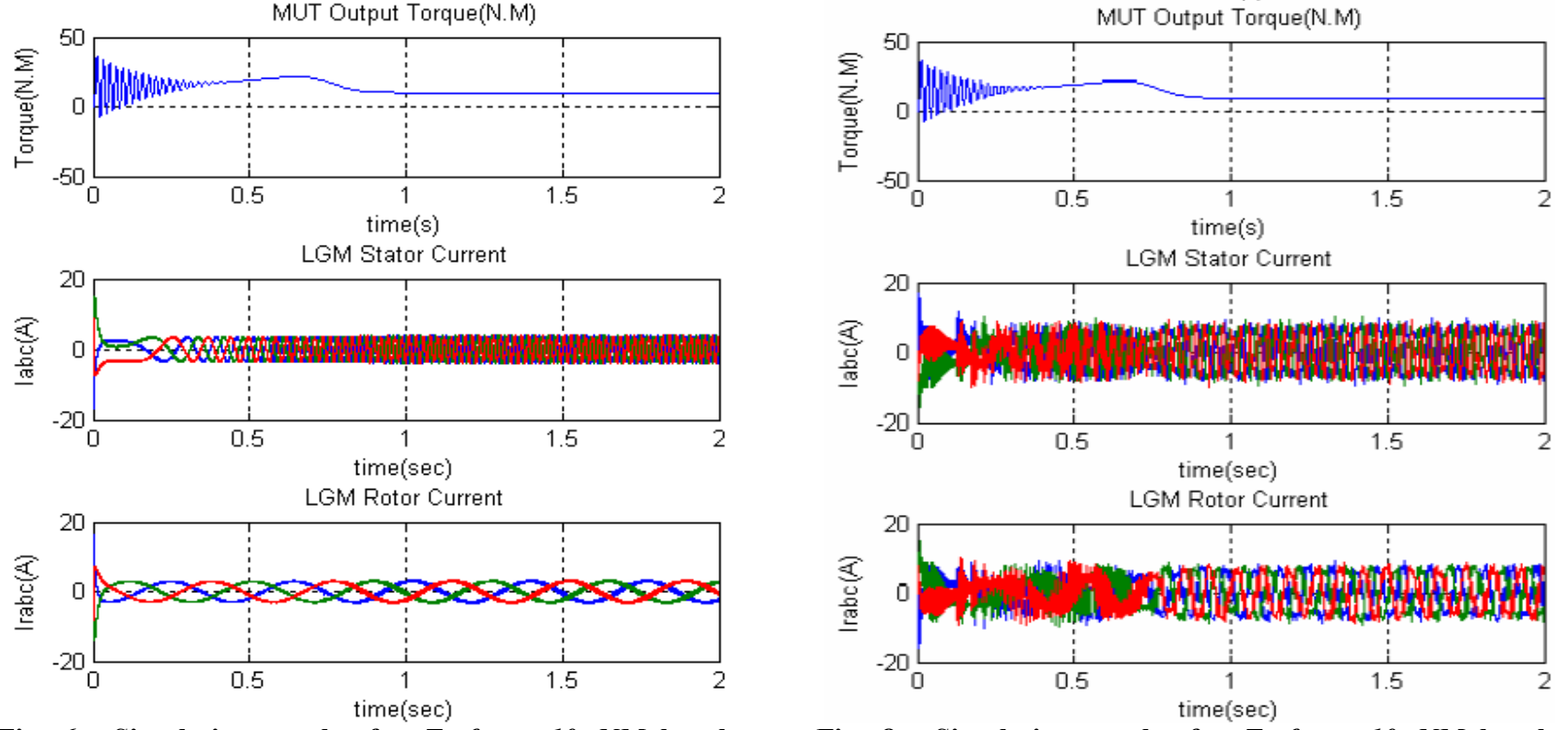

Fig. 6 Simulation results for Tref $=-10 N M$ by the conventional DTC: (a) output torque of MUT, (b) LGM stator current, (c) LGM rotor current.

Fig. 8 Simulation results for Tref $=-10 N M$ by the twelve-sector DTC: (a) output torque of MUT, (b) LGM stator current, (c) LGM rotor current. 
the mean of the LGM output torque is important, because electromechanical torque of MUT is considered and the performance of the MUT is under the argument. The output torque of MUT is roughly constant with varying ripple component of LGM torque.

The simulation results for $T_{r e f}=-10 N M$ by conventional DTC are shown in Figs. 5 and 6. Note that the torque ripple is acceptable with fine accuracy of output torque which is about $95 \%$ of the nominal value (19.8 NM).

Figs. 7 and 8 show simulation results for the proposed twelve-sector DTC with $T_{r e f}=-10 \mathrm{NM}$. In this case, some primary oscillations are present in the transient interval. To overcome this problem, it is proposed to set the reference torque to zero during the initial setup and to reset it back to its arbitrary value after reaching the steady state condition (final rotor speed).

The output torque ripple of LGM has now been decreased due to the reduced limit of the hysteresis block and thus, the output torque is achieved with a higher accuracy of $97 \%$.

Simulation results for a load profile characteristic that linearly varies with rotor speed, $T_{\text {ref }}=$ ${ }_{-} 0.4 / 3 \omega_{\text {final }} \mathrm{Nm}$ are shown in Figs. 9 and 10 and Figs. 11 and 12 for the conventional six-sector DTC and the proposed twelve sectors DTC, respectively. The proposed twelve-sector DTC has not made significant improvements since the transient state is significant in investigation of system behavior and cannot be eliminated. Nevertheless, as previously mentioned, these oscillations do not affect the ultimate performance of the system.

\subsection{Results for Dynamic Loads}

As most practical loads are dynamic, the performance of DTC is investigated for two types of dynamic loads, one with $J_{e m}>J_{l}$ and another with $J_{e m}<J_{l}$. It is predicted that with $J_{e m}>J_{l}$ the overall performance of load generator becomes sluggish since the inertia momentum has been increased, however, for
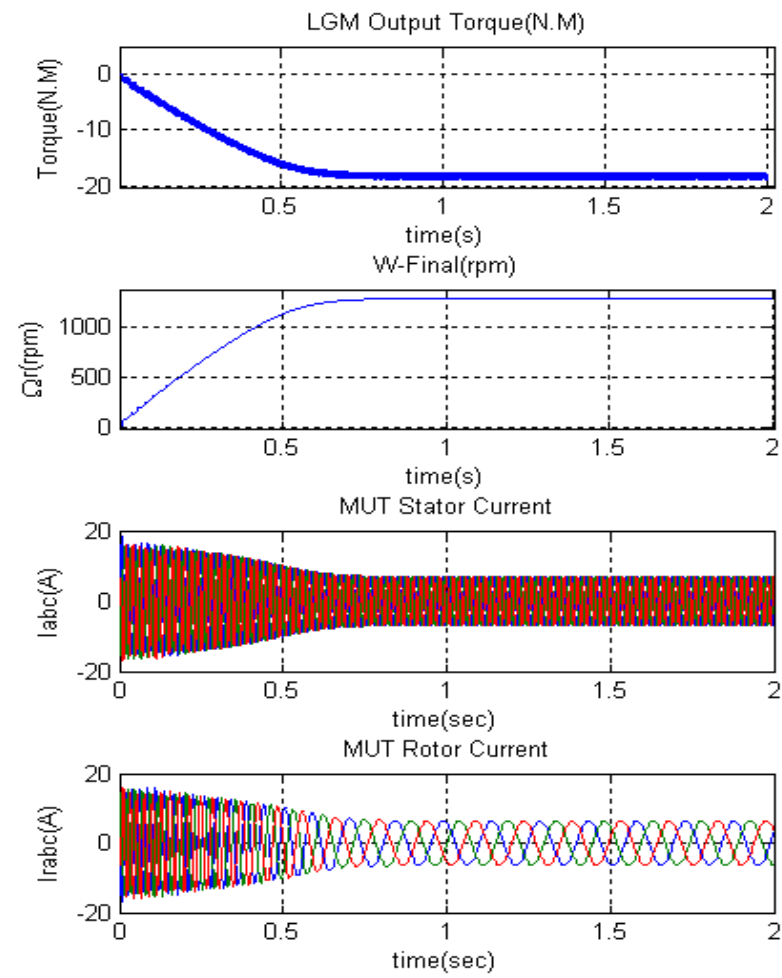

Fig. 9 Simulation results by the conventional DTC for Tref $=-0.4 / 3 \omega_{\text {final }} \mathrm{Nm}$ : (a) output torque of LGM, (b) final speed of the system, (c) MUT stator current, (d) MUT rotor current.
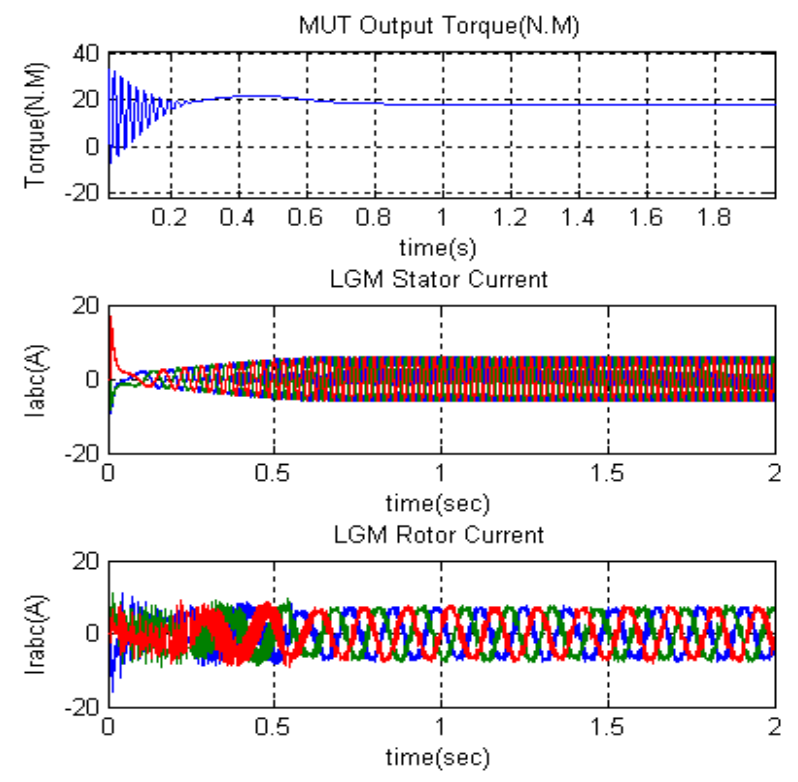

Fig. 10 Simulation results by the conventional DTC for Tref $=-0.4 / 3 \omega_{\text {final }} \mathrm{Nm}$ : (a) output torque of MUT, (b) LGM stator current, (c) LGM rotor current. 

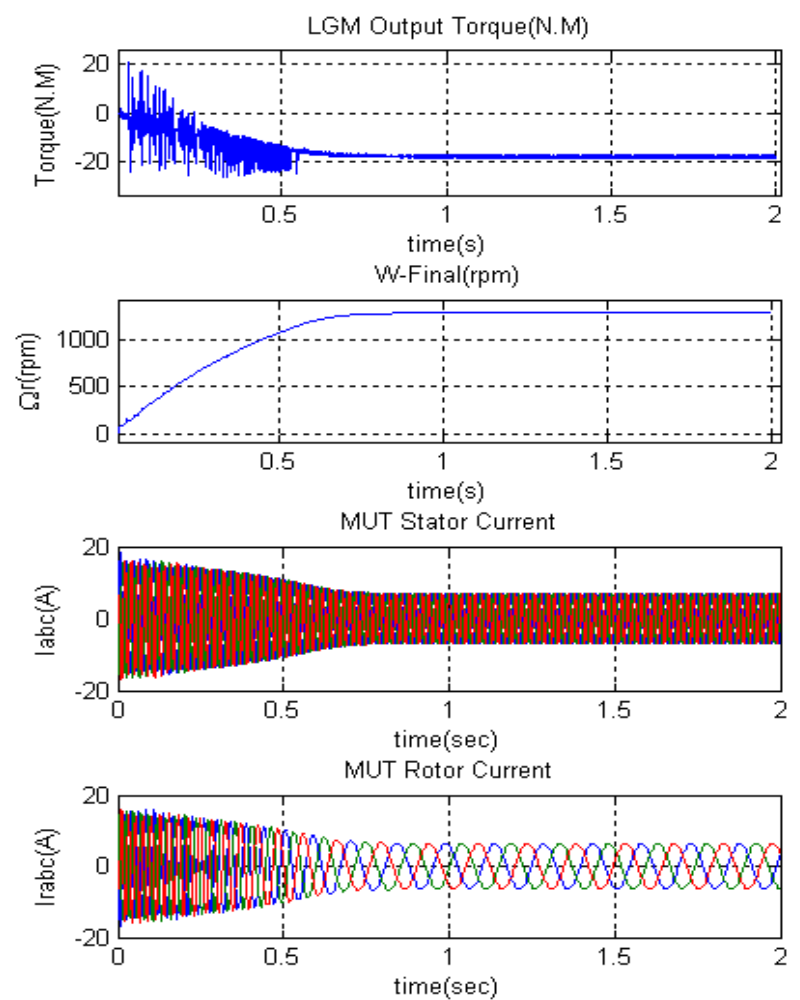

Fig. 11 Simulation results by the proposed twelve-sector DTC for Tref $=-0.4 / 3 \omega_{\text {final }} N m$ : (a) output torque of LGM, (b) final speed, (c) MUT stator current, (d) MUT rotor current.
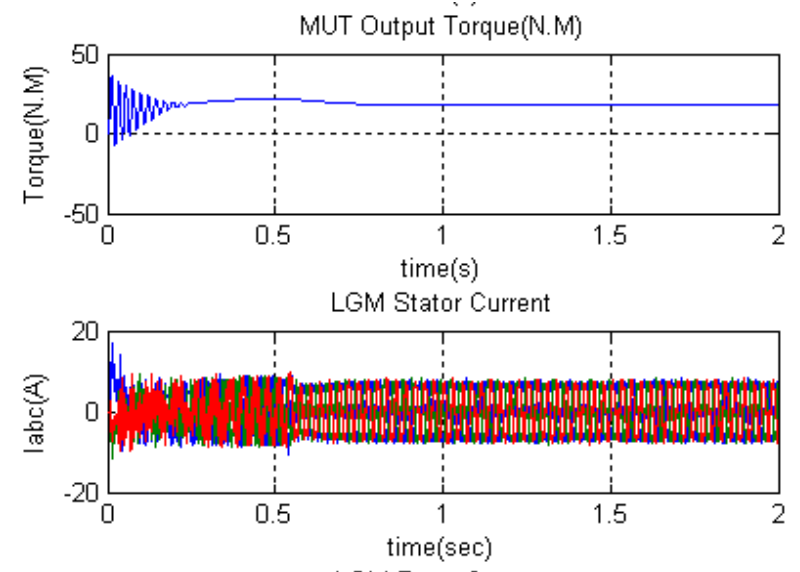

LGM Rotor Current

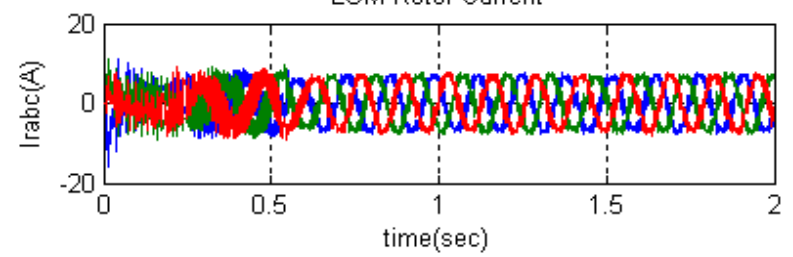

Fig. 12 Simulation results by the proposed twelve-sector DTC for Tref $=-0.4 / 3 \omega_{\text {final }} N m$ : (a) output torque of MUT, (b) LGM stator current, (c) LGM rotor current.
$J_{e m}<J_{l}$. The response time is expected to decrease. Simulations (Figs. 13-18) have been performed to demonstrate this behavior. Simulation results for $T_{\text {ref }}=-\left(10^{-5} \omega+210^{-6} \omega^{3}+0.2 J_{l} \cdot d \omega / d t\right) N m$ by using the conventional DTC method are shown in Figs. 17 and 18. It is apparent that the time required to reach the steady state speed has increased to about $t_{s S}=1.2 \mathrm{sec}$.

Note that early oscillations are due to the derivative of speed. These oscillations are due to the variations of reference torque because of speed variations in primary instances. As expected, the system has slower performance since $J_{e m}<J_{l}$ discussed above, only the first-half spectrum is used when simulation results for $T_{\text {ref }}=-\left(10+0.5 J_{l} \cdot d \omega / d t\right) \quad \mathrm{Nm}$ are also presented in Figs. 16 and 17. For this case, the total inertia momentum has been decreased since $J_{e m}<J_{l}$. The system can react faster and therefore, the required
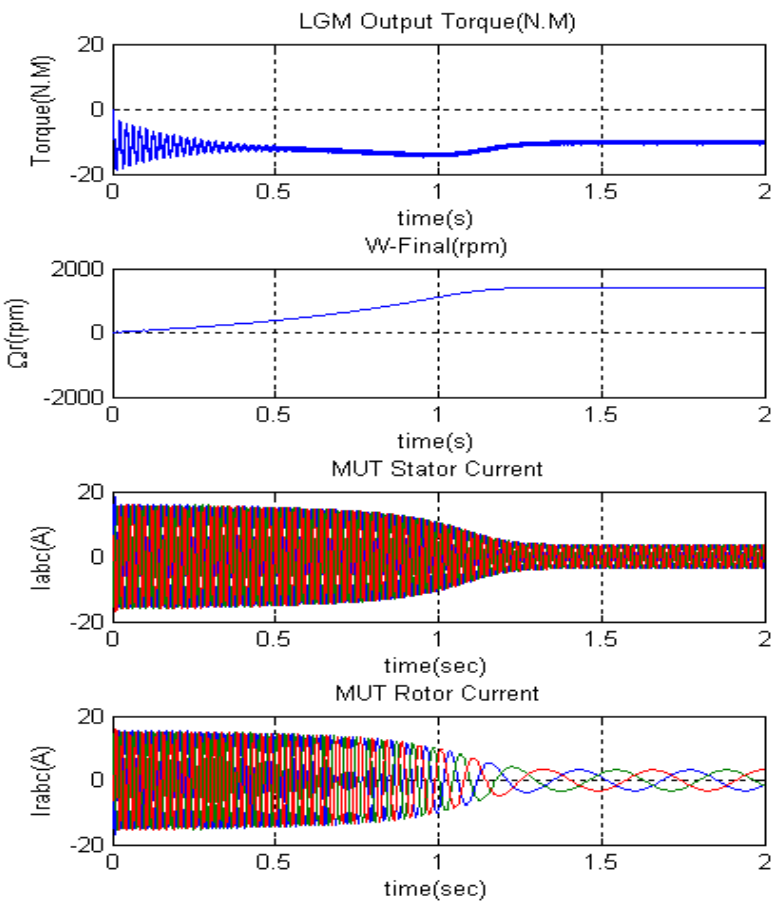

Fig. 13 Simulation results by the conventional DTC for $T_{\text {ref }}=-\left(10+2 J_{l} \cdot d \omega / d t\right) N m$ : (a) output torque of LGM, (b) final speed, (c) MUT stator current, (d) MUT rotor current. 

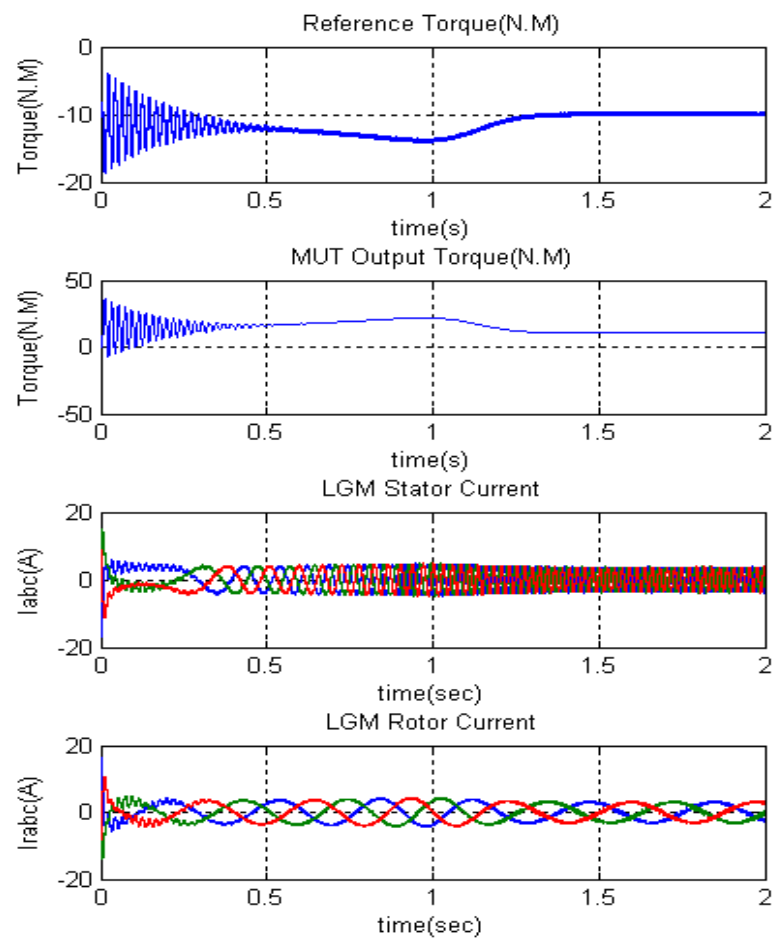

Fig. 14 Simulation results by the conventional DTC for $-\left(10+2 J_{l^{\cdot}} d \omega / d t\right) N m$; (a) the reference torque (b) output torque of MUT, (c) LGM stator current, (d) LGM rotor current.
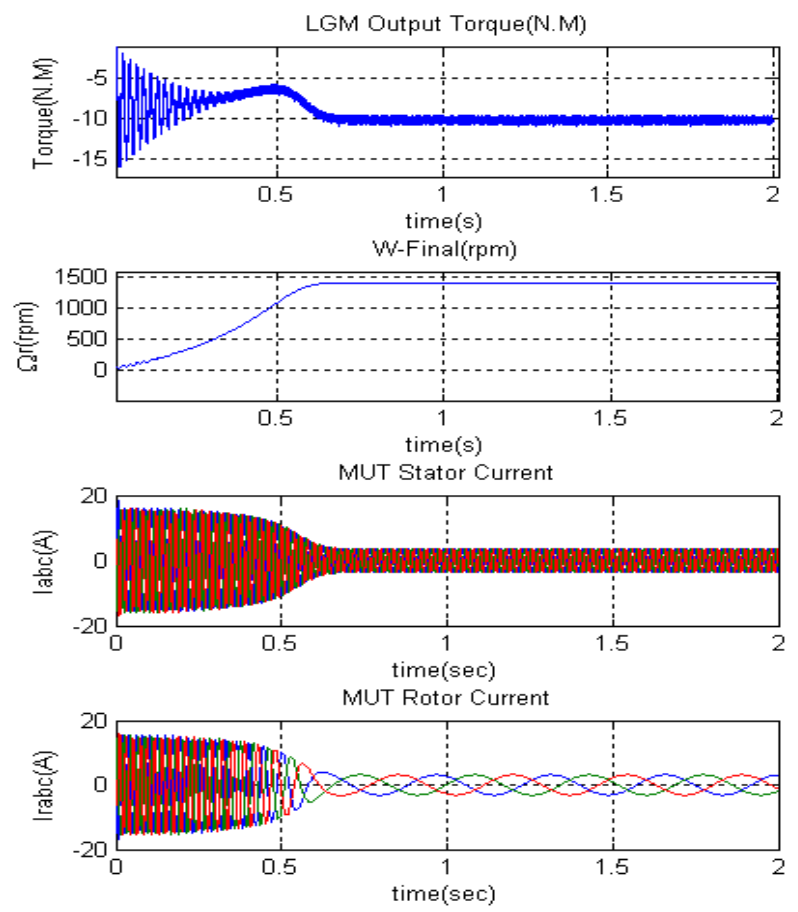

Fig. 15 Simulation results by the conventional DTC for $T_{\text {ref }}=-\left(10+0.5 J_{l^{\prime}} d \omega / d t\right) \mathrm{Nm}$ : (a) output torque of LGM, (b) final speed of the system (c) MUT stator current, (d) MUT rotor current.
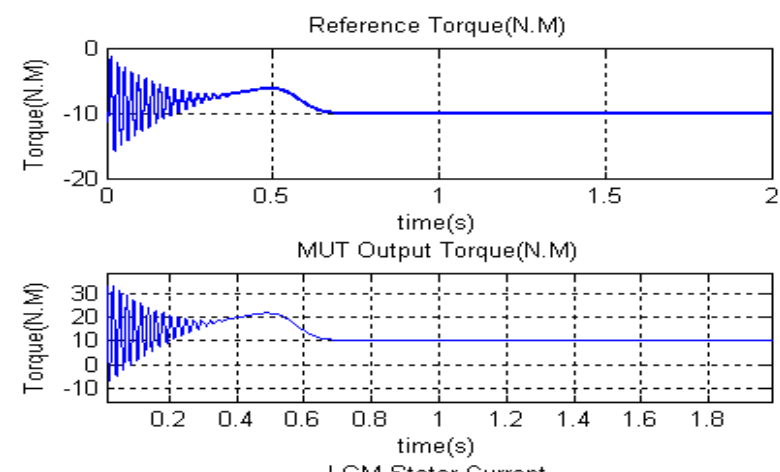

LGM Stator Current
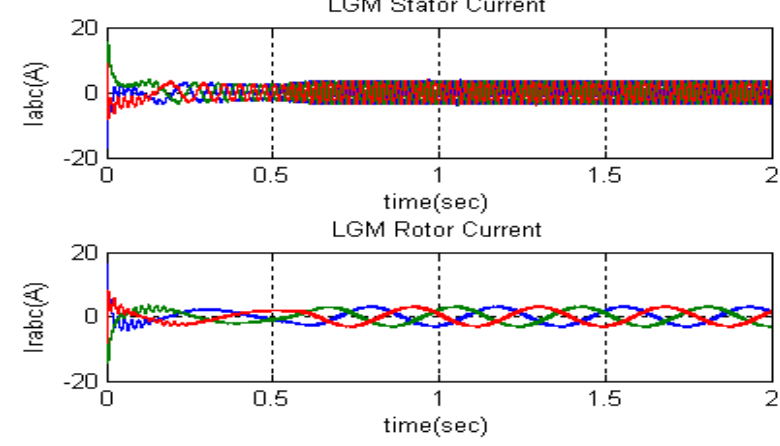

Fig. 16 Simulation results by the conventional DTC for $T_{\text {ref }}=-\left(10+0.5 J_{l} \cdot d \omega / d t\right) N m$ : (a) the reference torque (b) output torque of MUT, (c) LGM stator current, (d) LGM rotor current.

time for speed to reach its final value has been reduced. Note that $t_{s s}=0.75 \mathrm{sec}, t_{s s}=1.2 \mathrm{sec}$ and $t_{s s}=0.7 \mathrm{sec}$ for $J_{e m}=J_{l}, J_{e m}>J_{l}\left(J_{e m}=2 J_{l}\right)$ and $J_{e m}<J_{l}$, respectively. The minor oscillations (in steady state reference torque) are due to the small variation $J_{e m l}<J_{l} \mathrm{~s}$ in the output rotor speed.

Finally, a combination of the above mentioned dynamic loads with is exerted to LGM as the reference torque. Based on the simulation results (Figs. 17 and 18), the output torques of LGM and MUT have good accuracy and whereas $J_{e m}$ has been decreased to $0.2 J_{l}$, system has a faster response and the steady state time is decreased to $t_{s S}=0.5 \mathrm{sec}$.

\subsection{Response Time}

Although the vector control methods have good accuracy, they are not suitable for high speed applications due to their long response times. Therefore, the conventional vector control approaches cannot be engaged in applications requiring quick dynamics 

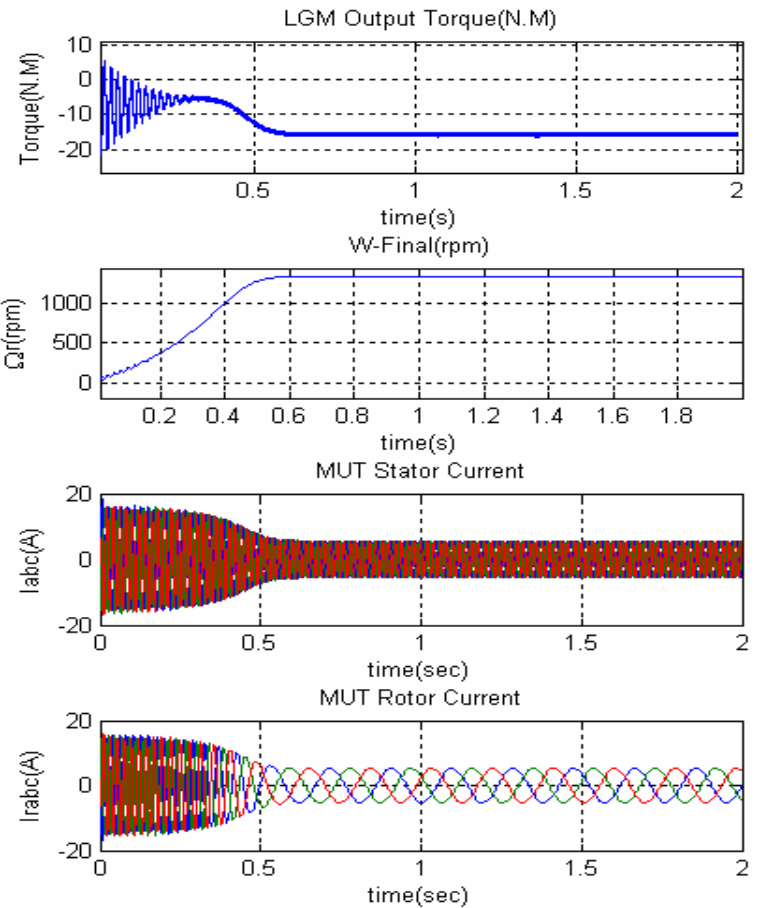

Fig. 17 Simulation results by the conventional DTC for $T_{\text {ref }}=-\left(10^{-5} \omega+210^{-6} \omega^{3}+0.2 J_{l} d \omega / d t\right)$ : (a) output torque of LGM, (b) final speed of the system (c) MUT stator current, (d) MUT rotor current.
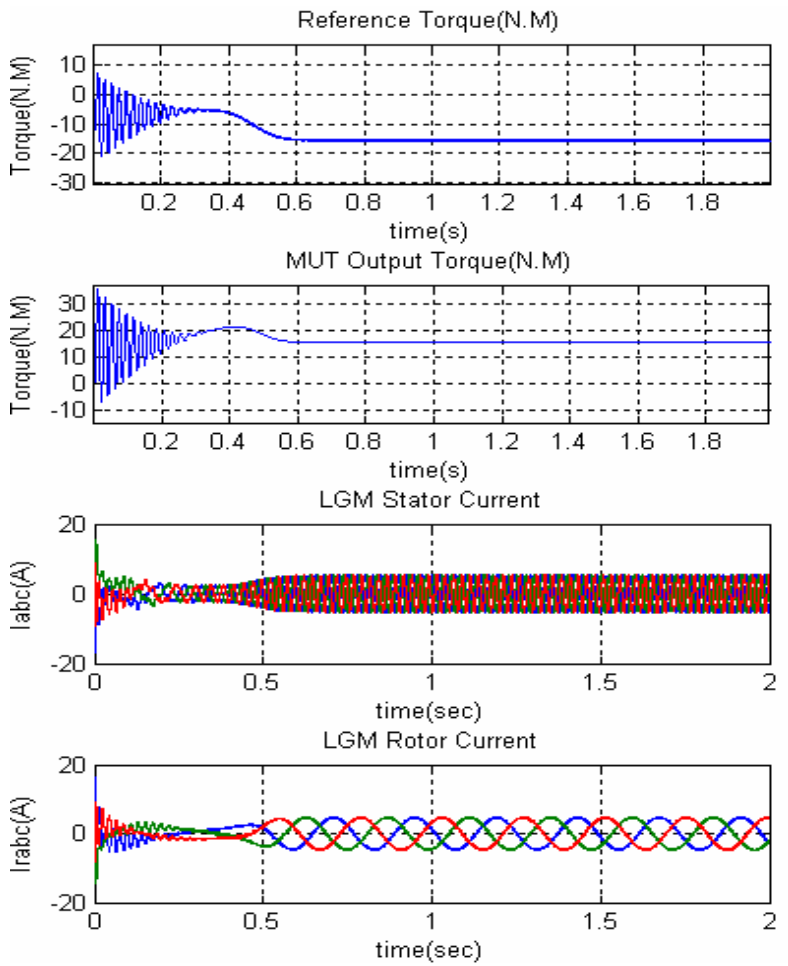

Fig. 18 Simulation results by the conventional DTC for $T_{\text {ref }}=-\left(10^{-5} \omega+210^{-6} \omega^{3}+0.2 J_{l} \cdot d \omega / d t\right)$ : (a) the reference torque (b) output torque of MUT, (c) LGM stator current, (d) LGM rotor current.

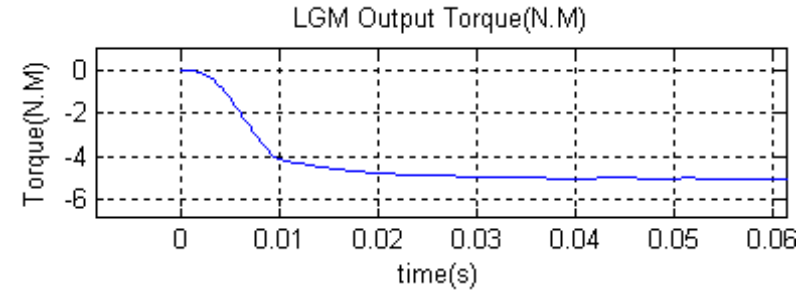

(a)

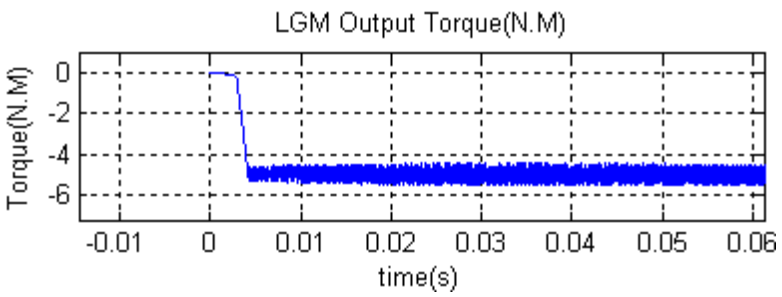

(b)

Fig. 19 Simulation results for $T_{r e f}=-\left(5+\omega^{2}\right) N m$ : (a) using DTC, (b) using vector control.

response such as the roll test of vehicles. DTC overcomes this limitation. To demonstrate this, simulations are performed for $T_{\text {ref }}=-(5+$ $\left.\omega^{2}\right) N m$ using DTC (Fig. 19a) and vector control (Fig. 19b) methods. As demonstrated, DTC produces faster response.

\section{Conclusion}

The new concept of load generator system based on DTC method is introduced, analyzed and simulated using various load profiles. Furthermore, the twelve-sector DTC method with 120 switching states is proposed that has higher accuracy of the final torque due to the increased switching frequency of $18 \mathrm{kHz}$. Some transient oscillations appear with the twelve-sector DTC, but they are damped during steady state conditions and will not disturb the ultimate performance that is related to output torque of MUT. Main conclusions are:

- DTC method is suitable for load generator systems. The static and dynamic characteristics of industrial linear and nonlinear loads can be modelled precisely for the motors and drives under test;

- Loads with electromechanical inertia momentum more than the LGM value, require more time to reach the steady state condition and vice versa; for loads with electromechanical inertia momentum less than the 
LGM value, the response time is decreased.

Main advantages of the proposed method as compared with conventional DTC approaches are:

- Precise following of the reference torque with an increased accuracy from $95 \%$ (for conventional DTC) to $97 \%$ due to the increased switching frequency;

- Shorter response time and smaller starting current of the load generator motor;

- Simpler approach with higher efficiency and shorter simulation time.

\section{References}

[1] Hadidi, R., Mazhari, I., and Kazemi, A. 2007. "Simulation of Induction Motor Starting with SVC.” 2007 2nd IEEE Conference on Industrial Electronics and Applications, Harbin, 1135-40.

[2] Vahedi, A., Mazhari, I., and Masoum, M. A. S. 2007. "Induction Motor Load Generator System Using Direct Torque Control Method." Power Engineering Conference, AUPEC 2007. Australasian Universities, Perth, WA, 1-6.

[3] Mahdi, M., Kouhanjani, M. J., Pourjafar, A., and Beladi, S. 2016. "An Interior Point Optimization Method for Stochastic Security-Constrained Unit Commitment in the Presence of Plug-in Electric Vehicles." Journal of Applied Sciences 16 (5): 189.

[4] Hadidi, R., and Vahedi, A. 2007. "A Comprehensive Approach to Investigate Parameters Sensitivity of Three Phases Induction Motors Using MATLAB/Simulink." 2007. ICEE '07. International Conference on Electrical Engineering, Lahore, 1-6.

[5] Biglarbegian, M., Nibir, S. J., Jafarian, H., and Parkhideh, B. 2016. "Development of Current Measurement Techniques for High Frequency Power Converters.” 2016 IEEE International Telecommunications Energy Conference (INTELEC), Austin, TX, USA, 1-7.

[6] Ziaeinejad, S., Sangsefidi, Y., Pairodin Nabi, H., and
Shoulaie, A. 2013. "Direct Torque Control of Two-Phase Induction and Synchronous Motors." IEEE Transactions on Power Electronics 28 (8): 4041-50.

[7] Jafarian, H., Parkhideh, B., and Bhowmik, S. 2016. "A Novel Comparative Robustness Index for Evaluating the Performance of Grid-Tied PV Inverters." 2016 IEEE 43rd Photovoltaic Specialists Conference (PVSC), Portland, OR, USA, 1254-9.

[8] Stoyanova I., Biglarbegian M., and Monti A., 2014. "Cooperative Energy Management Approach for Short-Term Compensation of Demand and Generation Variations.” 2014 IEEE International Systems Conference Proceedings, Ottawa, ON, 559-66.

[9] Azizi, H., and Vahedi, A. 2006. "Dynamic and Static Load Generator Based on Induction Motor Torque Tracking Control Method." ICEPOQ06.

[10] Tang, L., Zhong, L., Rahman, M. F., and Hu, Y. 2004. “A Novel Direct Torque Controlled Interior Permanent Magnet Synchronous Machine Drive with Low Ripple in Flux and Torque and Fixed Switching Frequency." IEEE Transactions on Power Electronics 19 (2).

[11] Jafarian, M. H., Parkhideh, B., Trivedi, S., and Bhowmik, S. 2015. "Locking Frequency Band Detection Method for Grid-Tied PV Inverter Islanding Protection." 2015 IEEE Energy Conversion Congress and Exposition (ECCE), Montreal, QC, 1976-81.

[12] Mazhari, I., Beghou, L., Enslin, J., Parkhideh, B., and Bhowmik, S. 2014. "Locking Frequency Band Exposure Method for Islanding Detection and Prevention in Distributed Generation." 2014 IEEE Energy Conversion Congress and Exposition (ECCE), Pittsburgh, PA, 4361-6.

[13] Mobarrez, M., Kashani, M. G., and Bhattacharya, S. 2016. "A Novel Control Approach for Protection of Multiterminal VSC-Based HVDC Transmission System against DC Faults." IEEE Transactions on Industry Applications 52 (5): 4108-16.

[14] Buja, G. S., and Kazmierkowski, M. P. 2004. "Direct Torque Control of PWM Inverter-Fed AC Motors-A Survey." IEEE Transactions on Industrial Electronics 51 (4): 744-7. 